\title{
OPERATIONAL ANALYSIS AND LIMITATIONS OF THE VSI-BASED MULTI-LINE FACTS CONTROLLERS
}

\author{
R.L. Vasquez-Arnez ${ }^{*}$
}

\author{
L.C. Zanetta Jr.*
}

\author{
${ }^{*}$ LSP/PEA - Electric Power and Automation Engineering Department \\ University of São Paulo \\ CEP 05508900 - São Paulo, SP
}

\begin{abstract}
In this paper, the operational analysis and the main limitations of the VSI-based multi-line FACTS controllers, namely: the GIPFC (Generalized Interline Power Flow Controller) and the IPFC (Interline Power Flow Controller), are analyzed. The GIPFC \& IPFC are amongst the newest devices within the FACTS technology. By utilizing these devices an enhanced and nearly instantaneous controllability over independent transmission systems, can be obtained. The steady-state analysis of a GIPFC \& IPFC controlling two balanced independent AC systems, is initially modeled. The use of the instantaneous power theory along with the $d-q$ orthogonal co-ordinates showed to be appropriate tools for assessing the GIPFC response towards the operation of both controlled systems. Yet, to observe its dynamic behavior and simultaneously validate the previous steady-state analysis, a phase-shift VSI-based GIPFC was implemented in the ATP program. Where applicable, a comparative evaluation between the GIPFC and the IPFC, is also presented.
\end{abstract}

KEYWORDS: FACTS, GIPFC, IPFC, Power Flow Control, VSI.

Artigo submetido em 29/10/2005

1a. Revisão em 07/02/2006

2a. Revisão em 19/06/2006

Aceito sob recomendação do Editor Associado

Prof. Carlos A. Castro

\section{INTRODUCTION}

Commonly, power systems present an inadequate line flow control which may result in overloaded lines, while other parts of the system, even the case of some neighboring lines, could be operating under an idle-like state. Hence the need for a better control of the power flow, thus, provide the network a higher degree of flexibility.

Recently, some new devices have been put forward within the FACTS technology, namely: the IPFC (Interline Power Flow Controller) and the GIPFC (Generalized Interline Power Flow Controller). By utilizing these devices, an independent controllability over each transmission line of a multiline system, can be achieved. With the cost of the high power semiconductors and converters declining steadily, both the GIPFC and the IPFC (Figure 1) appear as a stand out solution for the power flow control of multi-line systems, instead of using individually controlled UPFCs (Unified Power Flow Controller) in each line.

Despite the existence of some references on this subject (Gyugyi et alii, 1998; Hingorani and Gyugyi, 1999; Fardanesh et alii, 2000; Jianhong et alii, 2002; Diez-Valencia et alii, 2002 and Strzelecki et alii, 2002) the control ability that these devices present comes also accompanied with a certain degree of complexity in its structure, control system and the possible indirect effects that they may cause upon the network.

Similarly to the UPFC configuration, the shunt VSI (Voltage- 


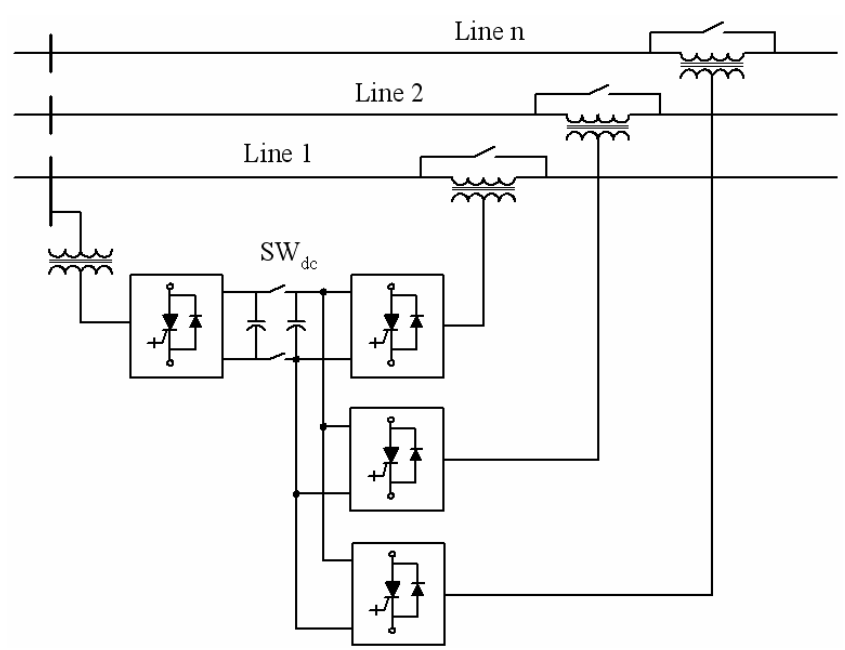

Figure 1: Generic representation of a GIPFC $\left(\mathrm{SW}_{d c}=\mathrm{ON}\right)$ and an IPFC \& STATCOM $\left(\mathrm{SW}_{d c}=\mathrm{OFF}\right)$

Sourced Inverter) within the GIPFC is in charge of fulfilling the real power demand established by the series inverters through the DC link, as well as to support the voltage of the bus where it is connected (Song and Johns, 1999; Sen and Stacey, 1998; Bian et alii, 1996). The series voltage injected to each line can be controlled in both its magnitude $\left(0 \leq V_{c_{-} i} \leq V_{c_{-} i}^{\max }\right)$ and phase angle $\left(0 \leq \theta_{c_{-} i} \leq 360^{\circ}\right)$. The subscript $i$ in these voltage and angle ranges refers to any of the series converters present in the whole system.

The GIPFC \& IPFC steady-state operation also requires that the sum of the active power, exchanged by the total number of converters, be zero. Under certain conditions such as when no voltage support in the substation bus is required, the shunt converter can be dispensed with and the GIPFC (now an IPFC) will be basically constituted by SSSCs (Static Synchronous Series Compensators) connected one to another through a common DC capacitor. In this case, the real power required for varying the angular position of the series voltages, will have to be supplied from one of the compensated AC systems. Under both configurations (GIPFC \& IPFC), the primary inverter(s) or assisted system(s), will have priority over the secondary inverter (within the assisting system) in achieving its set-point requirements.

\section{GIPFC \& IPFC MODELING AND ANALY- SIS}

The steady-state analysis developed in this section considers a GIPFC linking two balanced independent AC systems (Figure 2). For ease of analysis, the equivalent sending and receiving-end sources in both systems were regarded as stiff $\mathrm{AC}$ sources (infinite buses). It was also assumed that Sys-

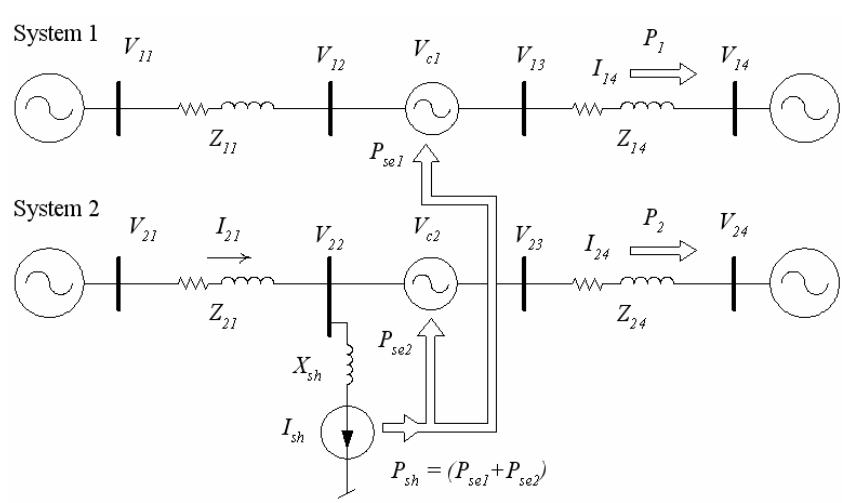

Figure 2: Elementary GIPFC system used in the analysis

tems 1 and 2 (or primary and secondary systems, respectively) have identical line parameters, although in practice they would usually be different. For heavy and simultaneous compensation in both systems, the shunt converter will have to be properly rated so as to attend the requirements of all the series inverters in operation. Another assumption regarded in this section is that each converter behaves as a shunt or series source operating with fundamental frequency and characterized by ideal sinusoidal waveforms (Uzunovic et alii, 1998; Vasquez-Arnez and Zanetta, 2005a).

The developed model makes use of the instantaneous power theory (Akagi et alii, 1984) and the $d_{s}-q_{s}$ orthogonal coordinates (Keri et alii, 1999). Both tools proved to be suitable for the steady-state analysis, as they facilitated the control of the direct and quadrature magnitudes of the ideal sources representing the inverters.

The power equality between the shunt and the series inverters, so as not to absorb nor to generate active power from or to the AC system, was strictly applied to the model. Thus, it can initially be established that:

$$
P_{s h}=\sum_{i=1}^{m} P_{s e \_i}
$$

In (1), $m$ stands for the total number of series converters. In our case $m=2$, therefore, using the $d_{s}-q_{s}$ orthogonal components of $I_{s h}$ and $V_{22}$ for the real power $P_{s h}$ (derived from bus $V_{22}$ ), it can be written:

$$
P_{s h}=V_{22 d} I_{s h d}+V_{22 q} I_{s h q}
$$

Similarly, the real power injected or absorbed by the series converters, regarding $V_{c 1}\left(V_{c 2}\right)$ and $I_{14}\left(I_{24}\right)$, will be: 


$$
\begin{aligned}
& P_{s e 1}=V_{c 1 d} I_{14 d}+V_{c 1 q} I_{14 q} \\
& P_{s e 2}=V_{c 2 d} I_{24 d}+V_{c 2 q} I_{24 q}
\end{aligned}
$$

Likewise, the reactive power injected (or absorbed, depending on the mode of operation) by the shunt converter can be expressed as:

$$
Q_{s h}=V_{22 d} I_{s h q}-V_{22 q} I_{s h d}
$$

So, from Figure 2 the following relations for Systems 1 and 2 can be written:

$$
\begin{aligned}
& V_{22(d, q)}+V_{c 2(d, q)}=Z_{24} I_{24(d, q)}+V_{24(d, q)} \\
& V_{12(d, q)}+V_{c 1(d, q)}=Z_{14} I_{14(d, q)}+V_{14(d, q)}
\end{aligned}
$$

Regarding the shunt current, $I_{s h}$, as being derived from bus $V_{22}$ :

$$
I_{21(d, q)}=I_{s h(d, q)}+I_{24(d, q)}
$$

also,

$$
V_{21(d, q)}-V_{24(d, q)}+V_{c 2(d, q)}=Z_{21} I_{21(d, q)}+Z_{24} I_{24(d, q)}
$$

similarly for System 1,

$$
V_{11(d, q)}-V_{14(d, q)}+V_{c 1(d, q)}=\left(Z_{11}+Z_{14}\right) I_{14(d, q)}
$$

Equations (6) through (10) are represented in a simple way only to shorten the set of equations. In order to relate them to eqs. (1) and (5), they should also be written in their $d_{s}-q_{s}$ components, which in this case coincide with the real and imaginary axis. By manipulating equations (1) through (10), it will be obtained a set of 10 equations (some of them nonlinear) that can be solved using any iterative method. Once computed the unknown variables (i.e. the $d_{s}-q_{s}$ components of $\left.V_{12}, V_{22}, I_{s h}, I_{14}, I_{24}\right)$, the power flow in the receivingend of Systems 1 and 2, with or without the series and shunt compensation effect, can be easily calculated through (11). The horizontal line above each variable in (11) and (12) denotes that such variables are phasors.

$$
\begin{gathered}
S_{1}=\left(P_{1}+j Q_{1}\right)=\bar{V}_{14} \bar{I}_{14}^{*} ; \\
S_{2}=\left(P_{2}+j Q_{2}\right)=\bar{V}_{24} \bar{I}_{24}^{*}
\end{gathered}
$$

In this model, the inclusion of the series transformers' coupling reactance $X_{s e(1,2)}$ within impedances $Z_{14}$ and $Z_{24}$, was only done to shorten the system equations. Once computed the line current $\left(I_{14}\right)$, the voltage $V_{13}$ can be calculated through (12). The bus voltage $V_{23}$ (System 2) can be obtained through a similar procedure.

$$
\bar{V}_{13}=\bar{V}_{12}+\bar{V}_{c 1}-j X_{s e 1} \bar{I}_{14}
$$

The GIPFC mathematical model developed in this section is also valid for the case of a classical IPFC configuration. Since the shunt VSI is no longer present in the secondary (assisting) system, some of the variables in the above equations will have to be zeroed (i.e. $I_{s h d}=0, I_{s h q}=0$ and $Q_{s h}=0$ ). Under this configuration, System 1 (master) will have two independently controlled variables (i.e. $\left.V_{c 1}, \theta_{c 1}\right)$. Conversely, System 2 (slave) will have to provide the series real power demanded by System 1, thus, leaving only one variable $\left(V_{c 2 q}\right)$ to be independently controlled. The above description implies that for the case of a classical IPFC scheme, the real power exchange of converter 2 is pre-defined (i.e. there exists a constraint for System 2) and therefore, only its series reactive compensation can utterly be utilized to control the power flow in this line (similar to the action of an SSSC).

\section{SIMULATION RESULTS}

In order to assess the effect and control ability of the GIPFC and the IPFC, it will be examined the behavior of the active power flow (which will follow the behavior of its respective line current) at the receiving-end of both systems.

The $P-Q$ plane results shown in Figure 3 were obtained using the mathematical model developed in Section 2. Each series angle $\left(\theta_{c 1}, \theta_{c 2}\right)$ corresponding to $V_{c 1}$ and $V_{c 2}$ were simultaneously varied from 0 to 360 degrees. The regions inside the ideal circle and inside the ellipse, correspond to the controlled area provided by $V_{c 1}$ and $V_{c 2}$, respectively. Among the reasons responsible for the obtention of the pattern showed in Figure 3(a), are: firstly, the real power demand of the series converter in System 1 (which must be fulfilled by the shunt converter) imposes a voltage variation to bus $V_{22}$, mainly to those series angles comprised in the range $\theta_{c 1} \approx 330^{\circ} \rightarrow 60^{\circ}$ and $150^{\circ} \rightarrow 240^{\circ}$, in which $P_{s e 1}$ demands a substantial amount of the exchanged real power. Secondly, the location of the shunt converter (i.e. modification of $Z_{21}$ ) in relation to the sending-end bus $\left(V_{21}\right)$ was also observed to be responsible for the obtention of this pattern. 


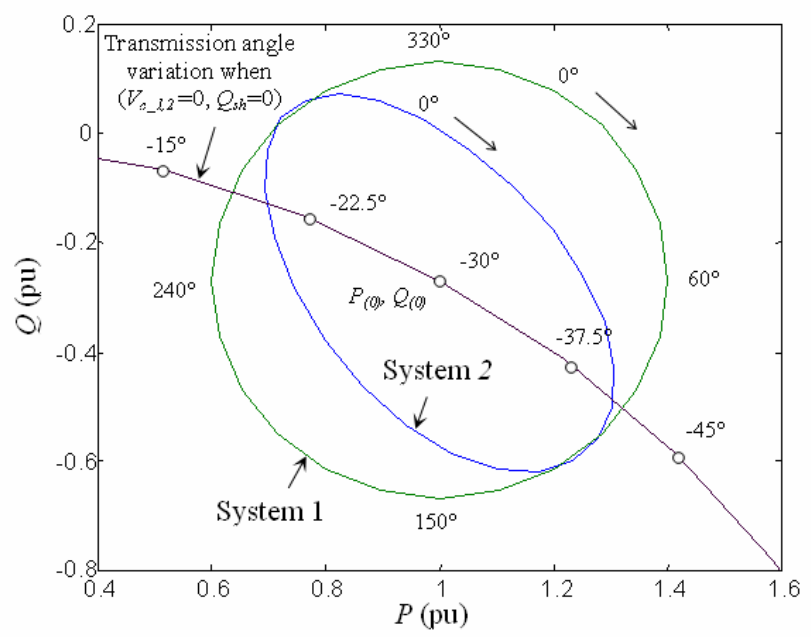

(a)

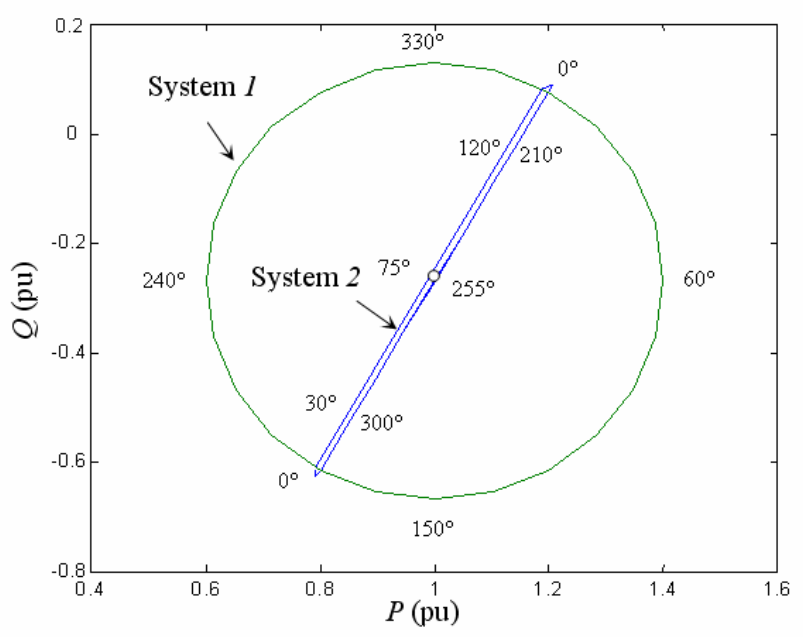

(b)

Figure 3: $P-Q$ plane at the receiving-end of Systems 1 and 2: (a) GIPFC with $V_{c 1}=0.2$ pu $\& V_{c 2}=0.15$ pu (b) IPFC case $\left(V_{c 1}=0.2 \mathrm{pu}\right) \& V_{c 2}=f\left(V_{c 1}\right)$

Should the shunt VSI be connected to an independent line, both Systems 1 and 2 will ideally present a circular control region as none of them will affect the other's voltage or power characteristics. A similar result will be obtained when $Z_{11}=Z_{21} \cong 0$, as in this case, voltages $V_{11} \& V_{21}$ (stiff sources) will take over from voltages $V_{12} \& V_{22}$, respectively.

Also in this case (Figure 3a), no shunt reactive power $\left(Q_{s h}=0\right)$ was applied to bus $V_{22}$. During the uncompensated condition (i.e. when $V_{c 1}=V_{c 2}=0$ ) the real and reactive power in each system (receiving-end) were equal to $P_{1(0)}=$ $P_{2(0)}=1.0 \mathrm{pu}$ and $Q_{1(0)}=Q_{2(0)}=-0.2679 \mathrm{pu}$, respec- tively. For all the simulated cases, the sending and receivingend sources in both systems were set to $V_{11}=V_{21}=1.0 \angle 0^{\circ}$ and $V_{14}=V_{24}=1.0 \angle-30^{\circ} \mathrm{pu}$.

Figure 3(b), shows the power flow behavior of a two-inverter IPFC in which $V_{c 2}$, due to the IPFC inherent operation, becomes a function of voltage $V_{c 1}$ (specified). The straight line observed in this result represents the power flow variation experienced by System 2 on account of the help provided to System 1 for manipulating its power flow.

The latter statement does not imply that inverter VSI-2 (System 2) will be unable to compensate simultaneously to its own line. It can execute local compensation with its available series reactive power. Under these conditions the straight line observed in Figure 3(b) will be shifted to the left (inductive mode) or to the right (capacitive mode of compensation), thus, establishing a square-like skewed area whose control region will again be limited by the capacity of the inverter. Recall that, quadrature voltage injection with respect to the line current, has predominant effect upon the line's real power flow. In-phase voltage injection has predominant effect on the line's reactive power flow and it is associated to the real power exchange between the converters (VasquezArnez and Zanetta, 2005b).

Notice that, as $V_{c 1}$ approaches to the quadrature position with respect to the line current (in our case $\theta_{c 1}=75^{\circ}, 255^{\circ}$ ) both $P_{2}$ and $Q_{2}$ on System 2 (Figure 3b), return to the uncompensated condition (i.e. $P_{2(0)} \& Q_{2(0)}$ ). This is due to the less (eventually null) demand in the exchanged power $\left(P_{s e 1}\right)$ between the series-connected VSIs (i.e. voltage $V_{c 1}$ is in quadrature with respect to $I_{14}$ ).

So, it can be stated that while the power flow in System $1\left(P_{1}\right)$ can be set to operate in an uncompensated mode at $P_{1(0)}=1.0 \mathrm{pu}$, with solely System 2 being compensated through $V_{c 2}$, the opposite operative condition (i.e. System 1 being compensated and System 2 kept unaltered) will present a drawback. That is, it is not possible to maintain unaltered the power flow over System 2 at $P_{2(0)}=1.0 \mathrm{pu}$, when solely System 1 is being compensated. This fact can be better observed in Figure 4. As the module of the series voltage in System 1 is increased $\left(V_{c 1}=0 \rightarrow 0.2 \mathrm{pu}\right)$ controlling effectively the real power $\left(P_{1}\right)$, the active power flow in System $2\left(P_{2}\right)$ becomes proportionally affected. Recall that $V_{c 2}$ and $P_{s e 2}$ are related through (4), in turn $P_{s e 2}$ and $P_{s e 1}$ are related through (1).

This voltage and power flow degradation that System 2 experiences was observed to occur in both FACTS devices. Yet, in the GIPFC configuration, the voltage variation that bus $V_{22}$ experiences, while helping to manipulate the series voltage $V_{c 1}$, can be largely controlled through the shunt converter's action. 

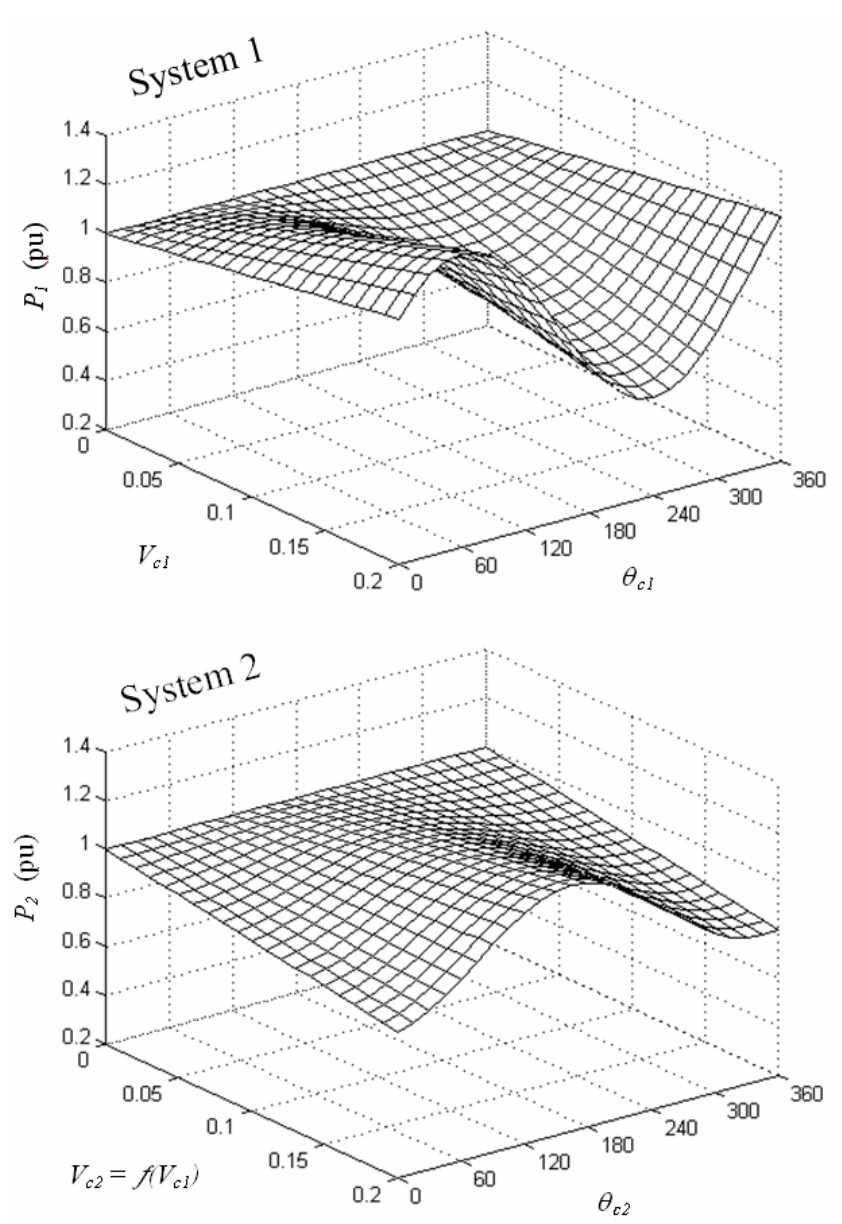

Figure 4: Power flow control in System 1 and its effect upon System 2 (uncompensated) when $V_{c 1}=00.2$ pu (IPFC configuration)

As for the IPFC configuration, it was also observed that independently of the inverters' position along the line, the effect of converter VSI-1 upon VSI-2 (unless the real power exchanged between them be zero), will occur.

The algorithm built in Matlab ${ }^{\circledR}$, related to the model presented in Section 2, enabled to explore and test some other operative conditions. For example, it was observed the condition when $V_{c 1}<V_{c 2}$ (e.g. $V_{c 1}=0.10$ pu or less and $V_{c 2}$ kept constant at $V_{c 2}=0.15 \mathrm{pu}$ ). Under this condition, System 1 (as expected) maintained its circular pattern within the ellipse. As for System 2, the condition $V_{c 1}<V_{c 2}$ (when $V_{c 1}=0.15 \rightarrow$ $0.0 \mathrm{pu}$ ) drew a lesser elliptical $P_{2}-Q_{2}$ region proportional to the value of $V_{c 1}$. Despite $V_{c 1}=0$, the operative region in System 2 did not draw a perfectly circular area, as inverters VSI-2 and VSI $_{s h}$ (Figure 5) will still be operating as a UPFC (Keri et alii, 1999 ), unless the series converter be modeled as an ideal source able to supply (or absorb) independently

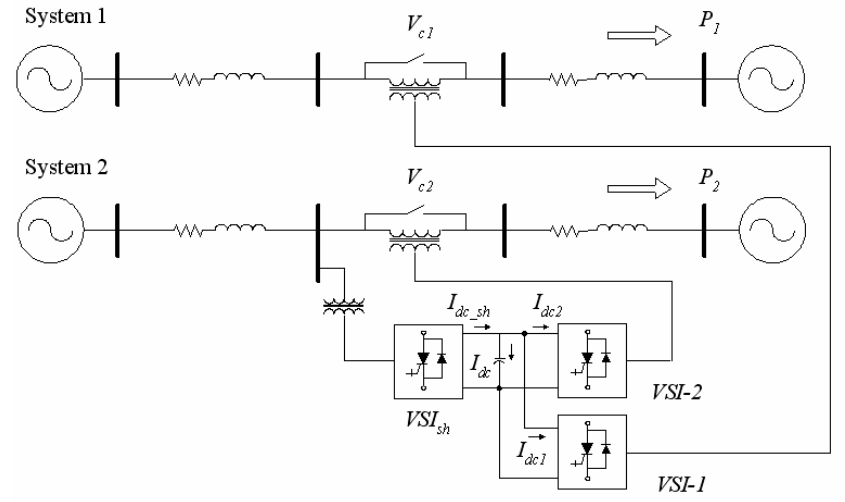

Figure 5: GIPFC scheme linking Systems 1 and 2

active and reactive power to (or from) the line.

\subsection{GIPFC \& IPFC Overall Control System}

The ATP program built to simulate the GIPFC scheme shown in Figure 5 is based upon the work published by VasquezArnez and Zanetta (2005a), where it was presented a UPFC using similar control techniques and features. The waveforms generated with the GIPFC scheme were obtained using a 12-pulse 3-level converter configuration that utilized the phase-shift control technique, with GTOs (Gate TurnOff thyristors) as switching devices. In this ATP program, both equivalent $\mathrm{AC}$ systems were assumed to operate at a rated voltage of $230 \mathrm{kV}$. The shunt converter's rated power was set to \pm 200 MVA, a fair amount to fulfil the maximum real power demand from both series VSIs (each with a rated power of $100 \mathrm{MVA}$ ) and to compensate, through its available shunt reactive power, the bus voltage $V_{22}$. The coupling transformers were chosen regarding firstly, the rated power of each converter and secondly, the DC link rated voltage which in our case was equal to $25 \mathrm{kV}$.

The GIPFC control system illustrated in Figure 6, used to built the ATP program, is based upon PI (ProportionalIntegral) controllers. For the sake of space limitations, it will be assumed that the sequence of the whole control block diagram presented can effortlessly be followed. Therefore, only the internal operation of the shunt and series controllers (control boxes) depicted in Figures 6(a) and (b), will be described.

Within the shunt controller illustrated in Figure 6(a) an error between the quadrature component of the measured $\left(I_{s h q}\right)$ and the specified $\left(I_{s h q}^{r e f}\right)$ shunt current, is initially established. This error is translated into an angle, which when added to $\theta$ (internally calculated by the PLL) will constitute the phase angle to be used in the firing control of the shunt converter. The real power absorbed by the shunt converter from the AC 


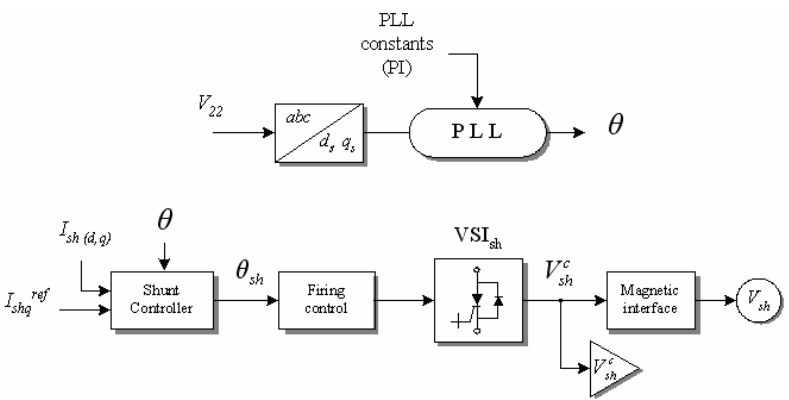

(a)

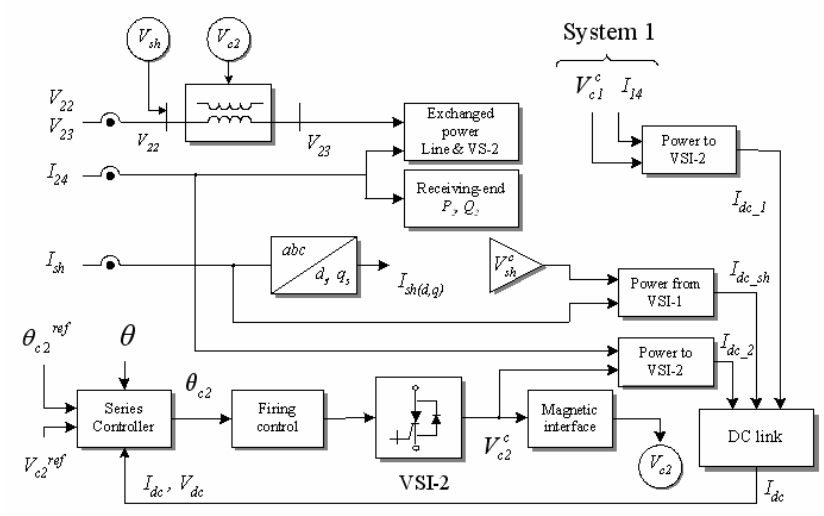

(b)

Figure 6: Control block diagrams of the: (a) shunt converter, (b) series converter

system is used to control the dc link voltage. The voltage $V_{s h}^{c}$ generated by $\mathrm{VSI}_{s h}$ will present a raw waveform, so before inserting it to bus $V_{22}$ it should be properly shifted (thus improved) by the magnetic interface (Vasquez-Arnez and Zanetta, 2002).

As for the series controller operation illustrated in Figure 6(b) the addition of $\theta$ and $\theta_{c 2}^{r e f}$ result in a preliminary angle. This angle, along with the so called dead angle (period between the positive and negative waveform and which determines the operation of an inverter either as a 3-level or 2level inverter) obtained from the relation between $V_{c 2}^{r e f}$ and $V_{d c}$, will constitute the phase angle used in the firing control of the series converter (Sen and Stacey, 1998). The control block diagram of the series converter in System 1, will be simpler than the control system presented for System 2. Recall that in the former, the shunt converter is dispensed with from the arrangement. Note also that in the ATP program used, unlike the program written in Matlab ${ }^{\circledR}$, it was specified $I_{s h q}$ instead of $Q_{s h}$.

Care must be taken during the implementation of the DC circuit which establishes the dependence between the shunt and the series inverters, as there must exist a continuous exchange between both converters. Neither unbalanced nor systems

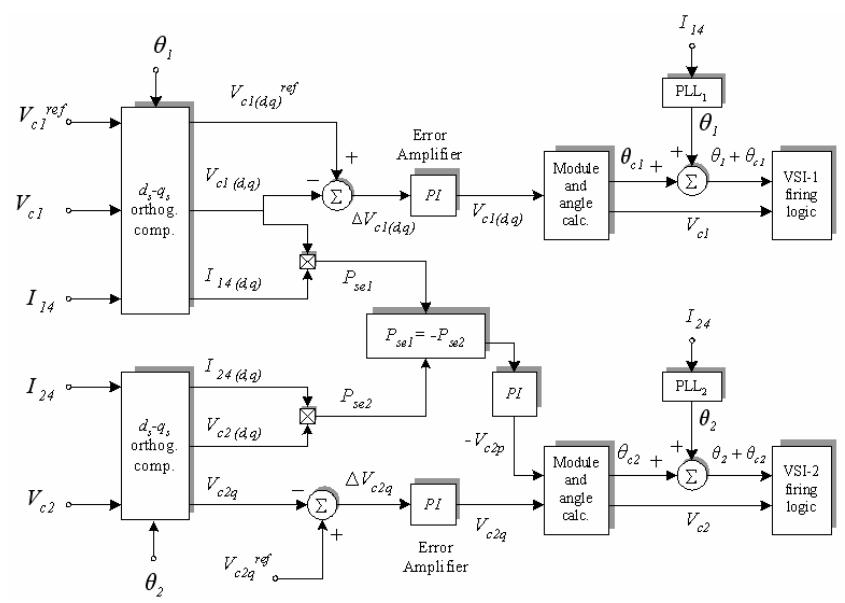

Figure 7: Control block diagram used in the IPFC configuration

having a high harmonic content can be accurately studied using the developed models, as they are based upon balanced system conditions and sinusoidal (or quasi sinusoidal) voltage and current waveforms. These aspects and conditions are left for further research.

The control system of the two-inverter IPFC illustrated in Figure 7, presents some differences in relation to the GIPFC case. Each VSI in the IPFC scheme is usually synchronized to its own line current through independent PLLs. By doing so, each VSI can independently supply series reactive compensation to its own line. That will also make possible the operation of any of the VSIs during contingency conditions when either converter (or system) is out of service.

Briefly, each angle $\theta_{1}$ and $\theta_{2}$ (calculated by its own PLL) are used to transform the input variables to their $d_{s}-q_{s}$ (orthogonal) components. The error between $V_{c 1(d, q)}^{r e f}$ and $V_{c 1(d, q)}$ (primary system) is amplified to calculate the module and angle of the preliminary series voltage. The final series angle used in the VSI-1 firing logic, is obtained from the addition of $\theta_{1}+\theta_{c 1}$. The real power $P_{s e 1}$ demanded by this inverter (VSI-1), which appears as a demand to be fulfilled by inverter VSI-2, is calculated using the instantaneous $p q$ power theory.

The negative sign of $P_{s e 2}$ stems from the constraint $\left(P_{s e 1}+P_{s e 2}\right)=0$. As the value of $P_{s e 1}$ is imposed by the primary (master) system, then the $V_{c 2 d}$ component can be obtained through (4). Recall that in the secondary (slave) system the $V_{c 2 q}$ component can be specified. Similarly to the case of System 1, the final series angle to be used by the converter's firing logic is obtained from $\left(\theta_{2}+\theta_{c 2}\right)$.

The results shown in Figures 8, 9 and 10, have been obtained using the GIPFC scheme shown in Figure 5. The power 


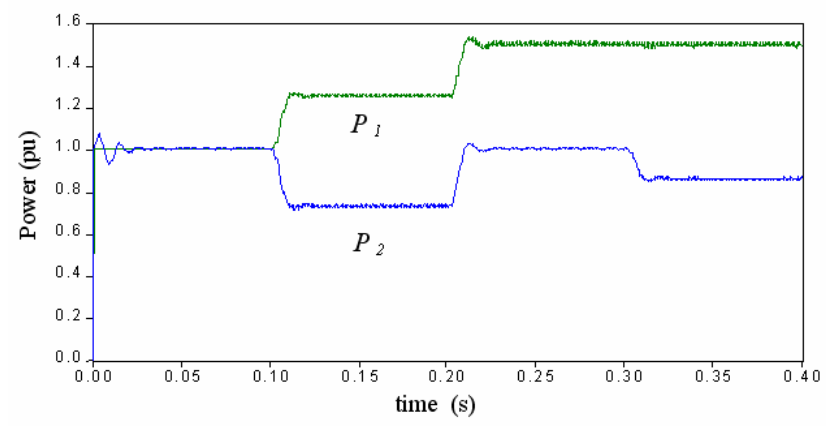

Figure 8: GIPFC power flow control over Systems $1 \& 2$, $V_{c 1}=0.10 \angle 60^{\circ}$ at $\mathrm{t}_{1}=0.1 s, V_{c 1}=0.20 \angle 60^{\circ}$ at $\mathrm{t}_{2}=0.2 s$, $V_{c 2}=0.10 \angle 240^{\circ}$ at $\mathrm{t}_{1}=0.1 s, V_{c 2}=0$ at $\mathrm{t}_{2}=0.2 s$ and $V_{c 2}=0.05 \angle 240^{\circ}$ at $\mathrm{t}_{3}=0.3 \mathrm{~s}$.

flow control sequence over both systems can be summed up as follows: due to system requirements at $\mathrm{t}=0.1 \mathrm{~s} P_{2}$ is reduced, whereas $P_{1}$ (System 1) is increased. Subsequently, the power flow reduction effect of $P_{2}$ is cancelled out ( $\mathrm{t}=0.2$ s) whereas $P_{1}$, on account of an hypothetical greater demand, is increased even more. The final control action occurs at $\mathrm{t}=0.3 \mathrm{~s}$ when $P_{2}$ is, due to a system requirement too, once again forced to reduce its transmitted power.

The amplitude variation of the series voltages injected $\left(V_{c 1}\right.$, $V_{c 2}$ ) characterizing the effect of the power flow behavior shown in Figure 8, can be observed in Figure 9.

On the other hand, Figure 10 shows the referred slight power flow degradation $\left(\Delta P_{2}\right)$ experienced by System 2 and which was mentioned in Section 3. The small oscillations observed at the beginning of each control action (points A \& B in Figure 10) are due to the PI (Proportional-Integral) controller adjustment and can be set and improved manually.

The GIPFC implemented in ATP provided to each line a high degree of controllability, as the transmitted power was simultaneously (and almost instantaneously) reduced or increased according to the operative needs of either system.

It should be noted that the multi-line FACTS controllers analyzed herein are primarily aimed to the power flow control. Nowadays, the FACTS technology offers various types of devices to cope with the various needs and applications within a power system, most of them still in the research stage, though. Problems existing within two independent asynchronous systems (or systems having different frequencies), for example, may well be tackled by using two shuntconnected VSIs whose DC sides are mutually connected (similarly to a back-to-back HVDC configuration). Still, some other problems such as system dynamic disturbances can be dealt with using series-connected VSIs, such as the

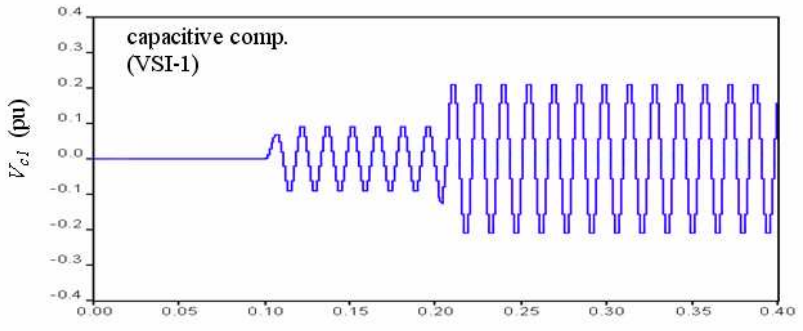

(a)

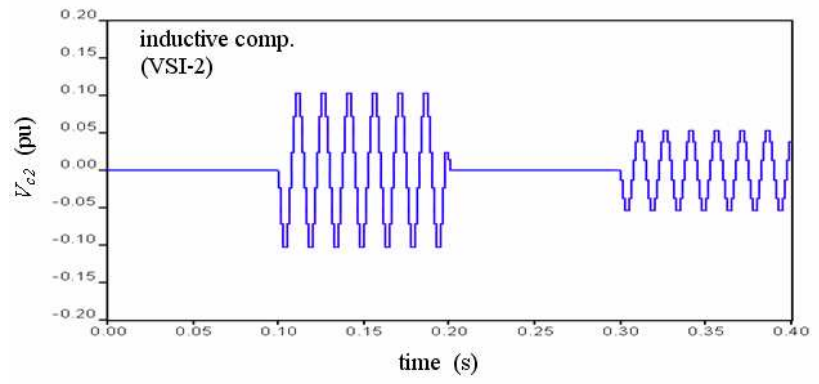

(b)

Figure 9: Series voltages $\left(V_{c 1}, V_{c 2}\right.$ injected to Systems 1 and 2

IPFC (Noroozian et alii, 1997).

\section{OPERATIONAL CONSTRAINTS}

Despite the benefits brought by the FACTS devices studied herein, there are also a number of operative constraints and limitations that should be accounted, like those described and explored in this section.

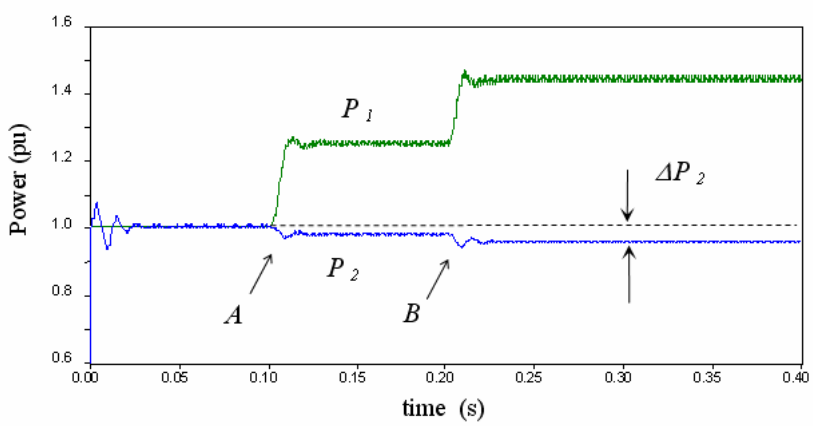

Figure 10: Power flow control over System 1, $V_{c 1}=0.10 \angle 60^{\circ}$ at $\mathrm{t}_{1}=0.1 \mathrm{~s}$ and $V_{c 1}=0.20 \angle 60^{\circ}$ at $\mathrm{t}_{2}=0.2 \mathrm{~s}, V_{c 2}=0$ 


\subsection{Line Voltage Limitations}

During steady-state, certain system restrictions can give place to limitations in the operative areas of both FACTS devices (GIPFC and IPFC). Such sub-areas, which will be referred to as NOAs (Non-Operative Areas), are due to the boundaries of voltages $V_{12}, V_{13}, V_{22}$ and $V_{23}$ shown in Figure 2 (which should not be violated).

Briefly, the module of each series voltage in the model presented in Section 2, was set to $V_{c 1}=V_{c 2}=0.2$ pu and rotated along the $360^{\circ}$. While doing so, there appeared values of $V_{12}, V_{13}, V_{22}$ and $V_{23}$ which were out of the operative voltage range imposed, thus, producing the NOA areas.

Figure 11, shows the NOA areas stemming from these voltage boundaries established $( \pm 10 \%$ of the nominal voltage in the referred buses, i.e. $0.9 \leq V_{i 2} \& V_{i 3} \leq 1.1 \mathrm{pu}$ ) which will in turn modify the ideally circular operative region of the series voltages injected. Although in our case voltages $V_{12}$ $\& V_{22}$ are internal voltages, in classical schemes they might represent the substation voltage. The smaller NOAs obtained for System 2 (Figure 11b), are because the bus voltage $\left(V_{22}\right)$ was compensated by the reactive power $\left(Q_{s h}\right)$ from the shunt VSI (capacitive mode), thus, improving its voltage limits.

As the series voltage magnitude $\left(V_{c 1}\right.$ or $\left.V_{c 2}\right)$ is increased, and if no other parameter in the system is altered, there will exist a trend among the NOA parabolic curves to cross each other, thus, increasing the NOA areas.

On the other hand, if voltages $V_{13}$ and $V_{23}$ would be more flexible in their voltage operation range, it could contribute to the reduction of the NOAs. Of course, this should be in accordance with the specifications of the line's maximum voltage withstanding capacity.

\subsection{Shunt Converter Rating Constraint}

An effect similar to that shown in Figure 11 (creation of non operative areas) will also occur in cases when the assisting converter's capacity (VSI $s h$ in the GIPFC case or the secondary system inverter in the IPFC configuration) can not fulfill the demand of the series VSIs. In that case, the shaded areas (NOAs) will slide further downwards in relation to the positions shown in Figure 11. The shunt converter's capacity is commonly determined by:

$$
M V A_{\text {shunt }}=\sqrt{\left(\sum_{i=1}^{m} P_{\text {se_i } i}\right)^{2}+\left(Q_{\text {shunt }}\right)^{2}}
$$

In a work published by Song et alii (2000), it is suggested that whenever a limit is going to be violated by a variable, it would be preferably to set the violated variable (in the remaining computation process) at its limiting value in order to achieve the highest efficiency of the compensator.

So, in line with the above statement and because the shunt VSI has a limited capacity, it was established that whenever

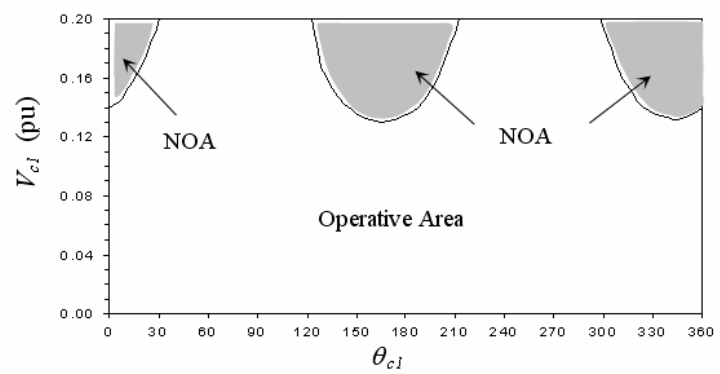

(a)

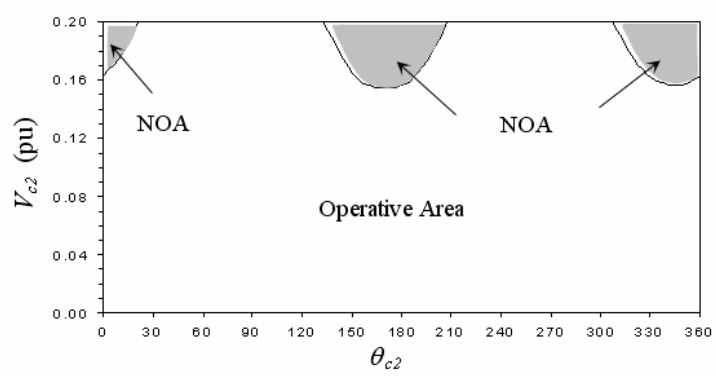

(b)

Figure 11: GIPFC Non-Operative Areas (NOA) corresponding to: (a) System 1, (b) System 2 with $Q_{s h}=0.1 \mathrm{pu}$.

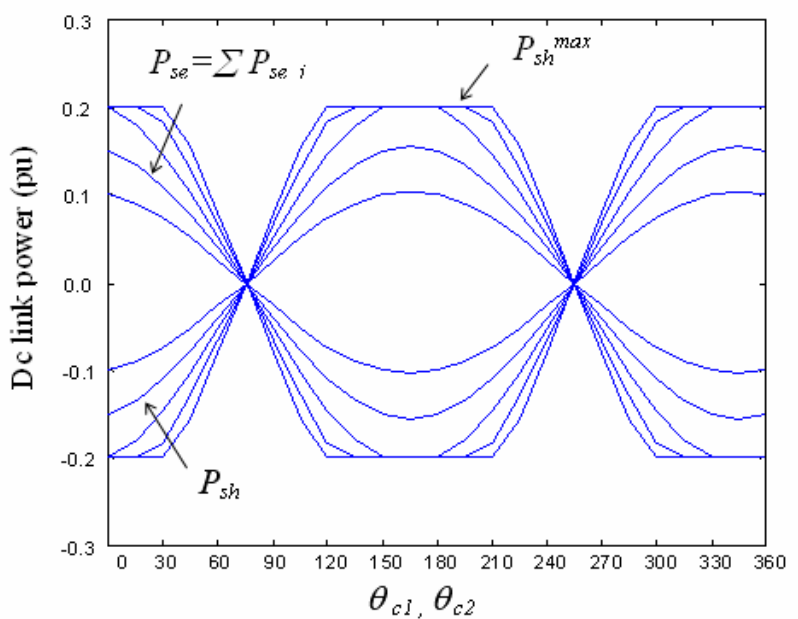

Figure 12: DC link power behavior due to shunt converter limited capacity 
the maximum rated real power was going to be surpassed, the exceeding value would be limited to its maximum value (e.g. $P_{s h}^{\max }= \pm 0.2$ pu as seen in Figure 12).

Figure 12, also shows the power balance between the shunt and the series inverters. Notice that any $P_{s e}$ curve (total power demanded by the series VSIs) along the full range of the series angles $\left(\theta_{c 1}, \theta_{c 2}\right)$ has an identical, but opposite, behavior (if losses within the inverters are neglected) than the real power supplied by the shunt converter $\left(P_{s h}\right)$. The $P_{s h}^{\max }$ limitation will impose a detrimental effect upon the series inverters' active power and thus on $V_{c 1}$ and $V_{c 2}$, creating non operative regions like those presented in Section 4.1. For the IPFC configuration, the real power limitation due to the secondary system's inverter rating, showed a similar result.

\subsection{Maximum Power Exchange through the DC-Link}

The maximum real power transferred through the dc-link by the inverter in the secondary system, can impose another restriction to the operation of the GIPFC and IPFC. Therefore, it is important to identify which will be the steady-state maximum power that can be exchanged through the dc-link to fulfill the demand of the series inverter(s). The power entering each series inverter (see the dc-link circuit of Figure 5), can be written as:

$$
P_{d c 1}=V_{d c} I_{d c 1} \quad ; \quad P_{d c 2}=V_{d c} I_{d c 2}
$$

Also, the AC side real power coming out from each inverter, can be expressed as:

$$
P_{s e 1}=\Re e\left(\bar{V}_{c 1} \bar{I}_{14}^{*}\right) \quad ; \quad P_{s e 2}=\Re e\left(\bar{V}_{c 2} \bar{I}_{24}^{*}\right)
$$

If the losses within the inverters are neglected, then (14) can be equated to (15). On the other hand, the line current over System 1 can be written as:

$$
\bar{I}_{14}=\left(\frac{\bar{V}_{11}+\bar{V}_{c 1}-\bar{V}_{14}}{j X}\right)
$$

where: $\mathrm{X}$ represents the equivalent series reactance of the line.

Manipulating equations (15) and (16), yield,

$$
\begin{aligned}
P_{s e 1}= & \frac{V_{c 1}}{X}\left[V_{11}\left(\sin \delta_{11} \cos \theta_{c 1}-\cos \delta_{11} \sin \theta_{c 1}\right)+\right. \\
& \left.V_{14}\left(\cos \delta_{14} \sin \theta_{c 1}-\sin \delta_{14} \cos \theta_{c 1}\right)\right]
\end{aligned}
$$

Similarly for System 2,

$$
\begin{aligned}
P_{s e 2}= & \frac{V_{c 2}}{X}\left[V_{21}\left(\sin \delta_{21} \cos \theta_{c 2}-\cos \delta_{21} \sin \theta_{c 2}\right)+\right. \\
& \left.V_{24}\left(\cos \delta_{24} \sin \theta_{c 2}-\sin \delta_{24} \cos \theta_{c 2}\right)\right]
\end{aligned}
$$

Notice that, due to an earlier assumption, the equivalent line reactance in (18) is similar to that of System 1. As for the IPFC analysis, the shunt VSI should be disconnected from the scheme (Figure 5). The derivative of (17) with respect to $\theta_{c 1}$ will allow us to calculate $\theta_{c 1}$, thus to obtain the maximum power $\left(P_{s e 1}^{\max }\right)$ corresponding to inverter 1 .

$$
\begin{gathered}
\frac{d P_{s e 1}}{d \theta_{c 1}}=\frac{d}{d \theta_{c 1}}\left\{\frac { V _ { c 1 } } { X } \left[V_{11}\left(\sin \delta_{11} \cos \theta_{c 1}-\cos \delta_{11} \sin \theta_{c 1}\right)+\right.\right. \\
\left.\left.V_{14}\left(\cos \delta_{14} \sin \theta_{c 1}-\sin \delta_{14} \cos \theta_{c 1}\right)\right]\right\}=0 \\
\theta_{c 1}=\tan ^{-1}\left(\frac{V_{14} \cos \delta_{14}-V_{11} \cos \delta_{11}}{V_{11} \sin \delta_{11}-V_{14} \sin \delta_{14}}\right)
\end{gathered}
$$

So, regarding the assumption made earlier on (in this section) about the converter losses, it can be considered that this maximum power will correspond to the power transferred via the DC link to the series inverter in System 1. As for the GIPFC configuration, a similar procedure, regarding the derivative of $P_{s e 2}$ with respect to $\theta_{c 2}$ and the substitution of $\theta_{c 2}$ into (18), will have to be realized for System 2. Finally, the total maximum power transferred by the shunt VSI will result from the addition of the $m$ (in our case two) series inverters' real power, as stipulated in (1).

\section{CONCLUSIONS}

The steady-state main control functions provided by the GIPFC and the IPFC upon two independent AC systems, was in this paper modeled and analyzed. Although in this work, it was considered the response of a GIPFC \& IPFC controlling only two AC systems, the study can well be extended and applied to multi-line systems. The performed analysis was based on the power balance among the converters when their losses are neglected. The main constraints related to their insertion into the network was also a matter of concern. For the GIPFC case, it was observed that the line voltage boundaries can give place to some non-operative regions of the series voltages, which in turn will affect the control area of the receiving end power flow. It was also observed the slight voltage and power flow degradation experienced by the system termed as secondary on account of fulfilling the control needs of the primary system(s). 
Finally, to evaluate the dynamic response and validate the initially developed fundamental frequency analysis, a 12pulse phase-shift VSI-based GIPFC, was also elaborated in the ATP program. The simulations performed and their results supported the steady-state model initially presented, as well as showed in a more stringent way the GIPFC capabilities and its associated drawbacks.

\section{REFERENCES}

Akagi, H.; Kanazawa, Y. and Nabae, A. (1984). Instantaneous Reactive Power Compensators Comprising Switching Devices without Energy Storage Components, IEEE Trans. on Power Industrial Applications, Vol. 20, No. 3, pp. 625-631.

Bian, J.; Ramey, D.G.; Nelson, R.J. and Edris, A. (1996). A Study of Equipment Sizes and Constraints for a Unified Power Flow Controller (UPFC). Proc. IEEE/PES-1996 Transmission and Distribution Conference, L.A., California, pp. 332-338.

Diez-Valencia, V.; Annakkage, U.D.; Gole, A.M.; Demchenko, P. and Jacobson D. (2002). Interline Power Flow Controller (IPFC) Steady State Operation. Proc. Canadian Conference on Electrical and Computer Engineering, IEEE CCECE 2002, Vol. 1, pp. 280-284.

Fardanesh, B.; Shperling, B.; Uzunovic, E. and Zelingher, S. (2000). Multi-converter FACTS Devices: the Generalized Unified Power Flow Controller (GUPFC). Proc. IEEE Power Engineering Society Summer Meeting, 2000, Vol. 2, pp. 1020 - 1025.

Gyugyi, L.; Sen, K.K. and Schauder, C. D. (1998). Interline Power Flow Controller Concept: A New Approach to Power Flow Management in Transmission Systems, IEEE Transactions on Power Delivery, Vol. 14, No. 3, pp. 1115-1123.

Hingorani, N.G. and Gyugyi, L. (1999). Understanding FACTS: Concepts and Technology of Flexible AC Transmission Systems, IEEE Press, N.Y.

Jianhong, C.; Lie, T.T. and Vilathgamuwa D.M. (2002). Basic Control of Interline Power Flow Controller. Proc. IEEE Power Engineering Society, Winter Meeting 2002, Vol. 1, pp. 521-525.

Keri, A.J.F.; Mehraban, A.S.; Lombard, X.; Eiriachy, A.; Edris, A.A. (1999). Unified Power Flow Controller (UPFC): Modeling and Analysis, IEEE Transactions on Power Delivery, Vol. 14, No. 2, pp. 648-654.

Noroozian, M.; Angquist, L.; Ghandari, M. and Anderson, G. (1997). Improving Power System Dynamics by
Series-Connected FACTS devices, IEEE Trans. Power Delivery, Vol. 12, pp. 1635-1641.

Sen, K.K. and Stacey, E.J. (1998). UPFC-Unified Power Flow Controller: Theory, Modeling and Applications, IEEE Transactions on Power Delivery, Vol. 13, No. 4, pp. 1953-1960.

Song, Y.H. and Johns, A.T. (1999). Flexible AC Transmission Systems - FACTS, IEE Press, London.

Song, Y.H.; Liu, J.Y. and Mehta, P.A. (2000). Strategies for Handling UPFC Constraints in Steady-State Power Flow and Voltage Control, IEEE Transactions on Power Systems, Vol. 15, No 2, pp. 566-571.

Strzelecki, R.; Benysek, G.; Fedyczak, Z. and Bojarski, J. (2002). Interline Power Flow Controller-Probabilistic Approach. Proc. IEEE $33^{\text {rd }}$ Annual Power Electronics Specialists Conference, PESC, Vol. 2, pp. 1037-1042.

Sun, J.; Hopkins, L.; Shperling, B.; Fardanesh, B.; Graham, M.; Parisi, M.; MacDonald, S.; Bhattacharya, S.; Berkowitz, S.; Edris, A. (2004). Operating Characteristics of the Convertible Static Compensator on the $345 \mathrm{kV}$ Network. Proc. IEEE-PES Power Systems Conf. and Exp., Vol. 2, pp. 732-738.

Uzunovic, E.; Cañizares, C. and Reeve, J. (1998). Fundamental Frequency Model of Unified Power Flow Controller. Proc. North American Power Symposium NAPS 1998, Cleveland, Ohio, pp. 294-299.

Vasquez Arnez, R.L. and Zanetta Jr. L.C. (2002). 48-Pulse Based SSSC (Static Synchronous Series Compensator) an Evaluation of its Performance. Proc. WSEAS International Conferences on: System Science, Applied Mathematics \& Computer Science and Power Engineering Systems, Rio de Janeiro.

Vasquez-Arnez, R.L. and Zanetta Jr, L.C. (2005a). Compensation Strategy of Autotransformers and Parallel Lines Performance, Assisted by the UPFC, IEEE Transactions on Power Delivery, Vol. 20, No. 2, pp. 15501557.

Vasquez-Arnez, R.L. and Zanetta Jr, L.C. (2005b). MultiLine Power Flow Control: An Evaluation of the GIPFC (Generalized Interline Power Flow Controller). Proc. $6^{\text {th }}$ International Conf. on Power Systems Transients - IPST'05, Montreal,

Wei, X.; Chow, J.H.; Fardanesh, B. and Edris, A.A. (2004). A Dispatch Strategy for an Interline Power Flow Controller Operating at Rated Capacity. Proc. PSCE 2004 - Power Systems Conference \& Exposition, IEEE PES, N.Y. 